\title{
Nutrient enrichment caused by marine cage culture and its influence on subtropical coral communities in turbid waters
}

\author{
Y.-C. A. Huang ${ }^{1,2}$, H. J. Hsieh ${ }^{3}$, S.-C. Huang ${ }^{1}$, P.-J. Meng ${ }^{4}$, Y.-S. Chen ${ }^{5}$, \\ S. Keshavmurthy ${ }^{1}$, Y. Nozawa ${ }^{1}$, C. A. Chen ${ }^{1,2,6, *}$ \\ ${ }^{1}$ Biodiversity Research Center, Academia Sinica, Nangang, Taipei 115, Taiwan \\ ${ }^{2}$ Institute of Oceanography, National Taiwan University, Taipei 106, Taiwan \\ ${ }^{3}$ Penghu Marine Biology Research Center, Fisheries Research Institute, Council of Agriculture, Makung 880, Penghu, Taiwan \\ ${ }^{4}$ National Museum of Marine Biology and Aquarium, Checheng, Pingtung 944, Taiwan \\ ${ }^{5}$ Department of Animal Science, National Ilan University, Ilan 260, Taiwan \\ ${ }^{6}$ ARC Centre of Excellence for Coral Reef Studies, James Cook University, Townsville 4810, Queensland, Australia
}

\begin{abstract}
The scale and intensity of marine cage culture have increased in the Asian-Pacific region, particularly in oligotrophic waters where coral reef organisms flourish. In this study, the influence of marine cage culture on subtropical coral communities in turbid waters was evaluated by measuring environmental parameters and benthic community compositions at Magongwan in the Penghu Islands, Taiwan. A canonical discriminant analysis of environmental parameters revealed that elevated levels of ammonium, nitrite, and chlorophyll a (chl a) released from the cages were the main pollution indicators that, in addition to sedimentation and turbidity, distinguished Impact Zone 1 (cage-culture zone) from the other 2 zones - Impact Zone 2 (800 m away from the cages) and the reference zone - in these turbid waters. Results of the canonical correlation analysis indicated that the coverage extents of macroalgae, sponges, and zoanthids were strongly correlated with levels of ammonium, nitrite, phosphate, chl $a_{1}$ and dissolved oxygen. Coral communities in Impact Zone 1 were mostly composed of stress-tolerant massive and submassive corals, but were lacking branching Acropora corals. In contrast, coral communities in the other zones, with high habitat complexity and species richness, were dominated by coral species with diverse morphologies, including branching Acropora coral communities. These results suggest that marine cage culture has been causing chronic nutrient enrichment in the surrounding waters at Magongwan, which may have resulted in a deterioration of suitable habitats for coral reef organisms. Nevertheless, intermediate levels of nutrients and particulate organic matter relative to the other zones might have been caused by the adjacent cage culture, resulting in the high coral coverage and diversity in the Impact Zone 2 in particular.
\end{abstract}

KEY WORDS: Marine cage culture $\cdot$ Benthic communities $\cdot$ Nutrient enrichment $\cdot$ Stress-tolerant corals $\cdot$ Eutrophication

\section{INTRODUCTION}

During the last 2 decades, marine cage culture adjacent to coastal coral reefs has become a prosperous industry and is increasing in scale and intensity in the Asian-Pacific region (Chen \& Hsu 2006). Eutrophica- tion caused by marine cage culture is a major environmental influence affecting conditions in the adjacent water column and sediments, even to the extent of altering benthic assemblages (Wu 1995, Karakassis et al. 2002, Yucel-Gier et al. 2007, Holmer et al. 2008). For example, massive amounts of waste feed and fecal 
material from cage culture are discharged into the surrounding waters as soluble inorganic matter or particulate organic matter (POM), deteriorating water quality, reducing dissolved oxygen (DO) levels, increasing sedimentation and turbidity, and changing the abundance and composition of microbial communities in the water (Wu et al. 1994, La Rosa et al. 2002, Paerl et al. 2003, Garren et al. 2008). As a consequence, long-term waste inputs can modify sediment physicochemical characteristics, increase the severity of marine diseases, affect coral-larval settlement and recruitment, and cause shifts in benthic assemblages (Brown et al. 1987, Weston, 1990, Bruno et al. 2003, Gao et al. 2005, Villanueva et al. 2006; reviewed in Loya 2007, Holmer et al. 2008). Degradation of coral reefs caused by eutrophication might also cause shifts in the dominant coral communities. In summary, nutrient enrichment stimulates macroalgal overgrowth enabling macroalgae to rapidly cover and smother living coral (Lapointe 1997, Costa et al. 2008). Furthermore, overgrowth of benthic filter feeders, such as bryozoans, sponges, and zoanthids, may outcompete corals for substrata, which results in a decrease in both diversity and abundance of hard corals and ultimately a phase shift from corals to macroalgae (Done 1992, McCook 1999). Macroalgal overgrowth of coral reefs is associated with a 'topdown' mechanism, in a similar way as is overfishing, that leads to a reduction in herbivory pressures and 'bottom-up' processes such as nutrient enrichment and sedimentation, which result in eutrophication (Jackson et al. 2001, Koop et al. 2001). Because overfishing is seriously affecting the 'top-down' mechanism globally, many studies emphasized the bottom-up process of macroalgal overgrowth due to extra nutrient supplies (Lapointe 1997, Jackson et al. 2001, Costa et al. 2008). In recent years, some studies reported that nutrient enrichment and particulate matter derived from fish farms enhanced the growth and reproductive potential of adjacent hard corals (Bongiorni et al. 2003a,b, Shafir et al. 2006, Amar \& Rinkevich 2007, Shaish et al. 2008). This finding challenges the traditional concept that eutrophication is generally harmful to coral reefs, and has led to debates on the effects of fish farms on adjacent coral reefs in the Gulf of Eilat, Red Sea (Loya \& KramarskyWinter 2003, Rinkevich et al. 2003, Wielgus 2003, Loya et al. 2004, Abelson et al. 2005, Rinkevich 2005a,b, Loya 2007). Therefore, the role of deteriorating water quality on corals is controversial, and the physiological and experimental support for reef declines caused by elevated nutrients remains unclear (Koop et al. 2001, Szmant 2002; referred to in Fabricius 2005). Marine cage culture has developed and expanded in Taiwan due to the over-harvesting of natural populations and increasing demands for food resources over the past 2 decades. In particular, extensive development of marine cage culture in the Penghu Islands (the Pescadores) was encouraged by the government in semi-enclosed embayments, such as Magongwan, where subtropical coral communities were once abundant (Chen 1999, Hsieh et al. 2001, 2007) and flourished in the turbid waters ( $\mathrm{Hu}$ et al. 1986). However, few studies have discussed the effects of nutrients and particulate matter from marine cage culture on coral and benthic communities in turbid waters. Due to a lack of a long-term monitoring program at Magongwan and based on information from local fisheries units that claim that macroalgal overgrowth only appeared after these fish cages were installed, we sought to address the putative influences of marine cage culture. Hence, this study was designed to determine the correspondence between the composition of benthic communities (including hard corals, macroalgae, and sponges/zoanthids) and environmental parameters in 2006-2007 at Magongwan. The aims of this study were (1) to determine potential environmental parameters responsible for possible marine environmental deterioration caused by marine cage culture, (2) to study the species compositions of benthic organism communities at Magongwan, (3) to disclose possible statistical relationships between these environmental parameters and benthic communities, and (4) to investigate the possibility of the deterioration of suitable habitats for coral reef organisms via benthic stress-tolerant organisms due to chronic effluent inputs.

\section{MATERIALS AND METHODS}

Study site. This study was conducted at Magongwan $\left(23^{\circ} 32^{\prime} \mathrm{N}, 119^{\circ} 33-36^{\prime} \mathrm{E}\right)$, a semi-enclosed embayment located in the south inner sea of the main island of Penghu (Fig. 1a), in the Taiwan Strait. Magongwan is surrounded by abundant subtropical coral communities, no river or industrial discharges are present, and the current, $<10 \mathrm{~cm} \mathrm{~s}^{-1}$, flows in a predominantly westto-east direction (measured in 2005). Marine cage culture at Magongwan has been in operation since the beginning of the 1990s and covers $\sim 15$ ha, with a maximum water depth of $\sim 20 \mathrm{~m}$. The cage culture consists of traditional raft net cages constructed of Styrofoam, which helps the cages float in the water and reduces damage from typhoons and strong monsoon winds. The cultivated species mainly include carnivorous fish such as cobia and grouper, and the mean fish yield over the past 4 yr (2005 to 2008) varied at 1400 to $2000 \mathrm{t}$ $\mathrm{yr}^{-1}$. Along the southern shoreline of Magongwan, 3 zones were selected for a benthic community survey 

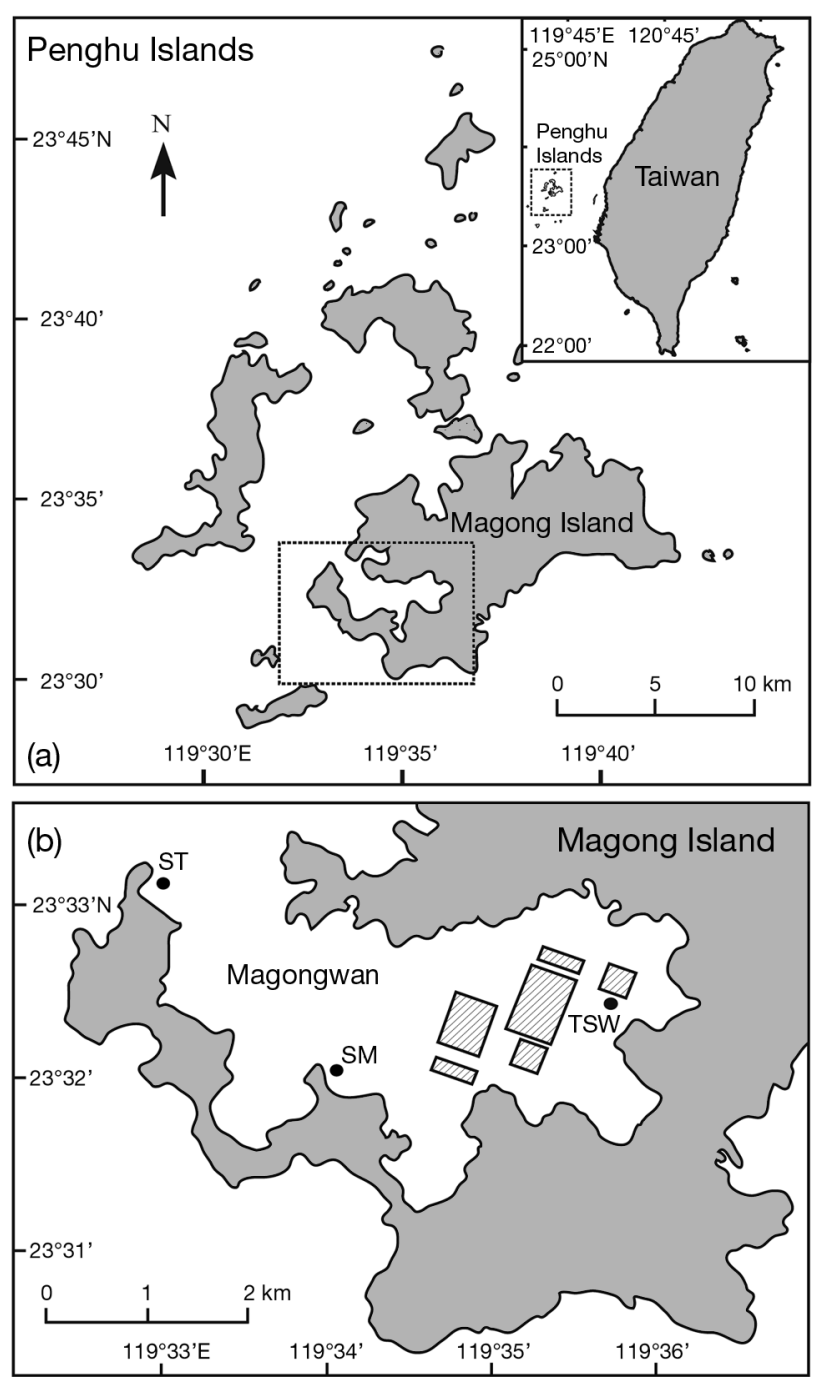

Fig. 1. (a) Penghu Islands. (b) Magong Island, southern coast. Sampled sites $(\bullet)$ : Tiesianwei $($ TSW) = Impact Zone 1 (IZ1), Shamaoushan $(\mathrm{SM})=$ Impact Zone 2 (IZ2), and Shertoushan $(\mathrm{ST}=$ reference zone). Hatched boxes: cage-culture areas

and bottom-water sample collection: (1) Impact Zone 1 at Tiesianwei (TSW) located $10 \mathrm{~m}$ from the cages, (2) Impact Zone 2 at Shamaoushan (SM) located at a distance of $800 \mathrm{~m}$ from the cages, and (3) a reference zone at Shertoushan (ST) located at the mouth of the embayment, $\sim 4.5 \mathrm{~km}$ away from TSW (Fig. 1b). In each zone, surveys and sampling were done at depths of 3 and $6 \mathrm{~m}$.

Environmental parameters. Total suspended solids (TSS), particulate organic matter (POM), ammonium, nitrate, nitrite, phosphate, dissolved oxygen (DO), chlorophyll (chl) $a$, and the sedimentation rate were examined as environmental parameters in this study. These parameters were determined by sampling bottom water at the 2 depths in each zone 5 times in
August and November 2006, and May, August, and December 2007. Triplicate water samples were taken at each site during every field sampling time. TSS were determined by filtering 11 of seawater through preweighed GF/C glass microfiber filters $(0.45 \mu \mathrm{m}$; Whatman) using a vacuum pump. Solids collected on the filters were washed twice to remove salts, then dried at $70^{\circ} \mathrm{C}$ until a constant weight was achieved, and weighed. Then the filters were ignited in a furnace at $450^{\circ} \mathrm{C}$ for $4 \mathrm{~h}$ to combust the organic matter contained in the solids. The resultant inorganic particulates on the filter were weighed and used as the POM content. A flow injection analyzer (FIA) and spectrophotometer (Hitachi U-3000) were used to determine concentrations of ammonia, nitrate, nitrite, and phosphate in the water samples (Meng et al. 2008). The DO concentrations were measured with a multiparameter monitoring instrument (YSI 600XLM; average of 3 readings at each sampling). Phytoplankton chl a was determined with a spectrophotometric method by filtering water samples through a Whatman GF/C glass microfiber and extraction in $90 \%$ aqueous acetone for $24 \mathrm{~h}$ at $4^{\circ} \mathrm{C}$ in the dark. The sedimentation rate was measured using PVC cylindrical sediment traps $(6 \mathrm{~cm}$ in diameter and $16 \mathrm{~cm}$ in depth, mounted on a metal base) that were deployed in each zone over a period of $\sim 2 \mathrm{~d}$ to cover a complete tidal cycle. The opening of the trap was at $\sim 30$ to $40 \mathrm{~cm}$ above the sea bottom. After collecting the traps, sediment in each trap was rinsed with distilled water to remove salts, filtered through a preweighed Whatman GF/C glass microfiber filter using a vacuum pump, and weighed.

Benthic community survey. The coverage of benthic organisms was surveyed using a belt transect $(30 \times$ $0.25 \mathrm{~m}$ ) at 2 depths ( 3 and $6 \mathrm{~m}$ ) in the 3 zones in August 2006. A series of photographic images was taken along a $30 \mathrm{~m}$ line using a $25 \times 25 \mathrm{~cm}$ PVC quadrate with a PVC rod that was fixed to an underwater digital camera housing. Six replicate transects were randomly placed at each depth site. Coverage of each replicate transect was analyzed using 24 photographic images chosen by simple random sampling. Coverage extents of 3 categories of benthic organisms including macroalgae, sponges/zoanthids, and coral in the images were determined using the Coral Point Count with Excel extensions (CPCe; v3.5) software (Kohler \& Shaun 2006), with 50 random points overlaid on each photographic image. Corals were identified to species level.

Composition of coral communities and conservation values. The conservation value (Edinger \& Risk 2000) was used to evaluate and compare conditions of reef coral communities at the 6 surveyed sites ( 2 depths $\times 3$ zones) at Magongwan. The proportion of coral species with different categories of colony mor- 
phologies representing $r, K$, and S strategists were recorded based on the classification system proposed by Edinger \& Risk (2000). Each group represents its own unique ecological characteristics: $r$ comprises weed-like ruderals, $\mathrm{K}$ represents competitors, and $\mathrm{S}$ consists of stress-tolerators. The composition of each coral community was then plotted on an r-K-S ternary diagram, and its position in a conservation class (CC) was determined. Among conservation classes, CC1 represents coral communities dominated by stresstolerators ( $\mathrm{S}$; mainly massive and submassive corals), CC2 represents coral communities dominated by competitors ( $\mathrm{K}_{\text {; }}$ mainly foliose and branching nonAcropora corals), CC3 represents coral communities dominated by ruderals ( $\mathrm{r}$; mainly branching and tabular Acropora), and CC4 represents coral communities with mixed coral morphologies or functional groups. Reefs with the highest conservation value (CC4) represent optimum communities for conservation. Reefs with moderate conservation values (CC2 and CC3) are also appropriate areas for conservation, while those with a lower conservation value (CC1) indicate extensive reef degradation and are not suitable for conservation (Edinger \& Risk 2000).

Statistical analysis. A 2-way analysis of variance (ANOVA) followed by Fisher's least significant difference (LSD) test was used to determine differences in coverage of benthic organisms (corals, macroalgae, and sponges/zoanthids) between the 2 depths (3 and $6 \mathrm{~m}$ ) and among the 3 zones (TSW, SM, and ST). Normality and homogeneity of variance were tested using a Kolmorogov-Smirnov test and Bartlett's test. In this study, a canonical discriminant analysis (CDA) was used to distinguish the 6 sampling sites and determine the discrimination power of the environmental parameters. CDA determines how a set of quantitative variables can differentiate among many known classes and yields linear functions of quantitative variables that maximally separate 2 or more groups of individuals while minimizing variations within groups. It also allows relationships among groups to be graphically represented by plotting the discriminant scores of sample observations (Shrestha \& Kazama, 2007). Because environmental parameters have various units, the CDA was applied to the data that had been standardized by z-scale transformation to prevent misclassification. Relationships between the coverage of benthic organisms and environmental parameters were determined using a canonical correlation analysis (CCA). The CCA was computed using square roottransformed values in order to minimize differences in variance produced by differences in the absolute size and to adjust for nonhomogeneity of variance among variables. All statistical analyses were done using SPSS 12.0 for Windows.

\section{RESULTS}

\section{Environmental parameters}

Data of the environmental parameters are summarized in Table 1. Ranges of nutrient concentrations $(\mu \mathrm{M})$ at Magongwan were 0.05-0.71 for phosphate, 0.70-4.32 for nitrate, $0.03-0.40$ for nitrite, and 0.33-5.63 for ammonium. Maximum values of nutrients were generally observed in Impact Zones 1 and 2, while minimum concentrations were measured in the reference zone. Although nutrient concentrations fluctuated during the sampling period, results of 1-way ANOVA indicated that levels of ammonium, nitrate, and phosphate in Impact Zone 1 were significantly higher than those of the other reef zones $(p<0.05)$. Further, DO values ranged from 4.15 to $9.54 \mathrm{mg} \mathrm{l}^{-1}$ in the impact zones, and 6.01 to $10.03 \mathrm{mg} \mathrm{l}^{-1}$ in the reference zone. Particular in Impact Zone 1, the lowest values were detected when compared with others zones (1-way ANOVA, p < 0.05). The sedimentation rate at Magongwan strongly fluctuated between 5.86 and $84.12 \mathrm{~g} \mathrm{~m}^{-2} \mathrm{~d}^{-1}$, and represented the results that there was no significant difference between these sampled zones (1-way ANOVA, p = 0.17). The discriminant potencies of environmental parameters in 2006 and 2007 in the CDA are shown in Fig. 2. Canonical correlation coefficients were $0.86(p<0.01)$ for the first canonical discriminant function (CDF1) and 0.56 ( $\mathrm{p}<$ 0.05) for CDF2 (Table 2). The CDF1 explained 81.09\% of the variance and discriminated Impact Zone 1 from the other zones, while CDF2 explained $12.45 \%$ of the variance and efficiently separated the 2 depths of Impact Zone 1. These 2 CDFs together explained $93.54 \%$ of the variance in the 6 sampled zones. The CDF1 had the highest canonical correlation coefficient (0.86), because it was defined by the 4 discriminant variables of chl $a, \mathrm{DO}$, ammonium, and nitrite, the canonical coefficients of which had high absolute values (Table 2). Moreover, the canonical structure coefficients in CDF1 indicated that the variance of variables with the highest discriminant power were nutrients (nitrite, phosphate, and ammonium) and chl a. At Magongwan, nutrients (ammonium and nitrite) can be used to distinguish these 6 sampled reef zones and explained $81.09 \%$ of the total variance of environmental parameters compared to other physical factors, such as suspended solids and the sedimentation rate.

\section{Coverage of benthic organism communities}

Coverage extents of reef corals, macroalgae, and sponges/zoanthids in 2006 are shown in Fig. 3. Results of a 2-way ANOVA showed that there were significant 
Table 1. Environmental parameters (range and mean $\pm \mathrm{SE} ; \mathrm{n}=15$ ) for the 3 sampled reef zones at Magongwan (Impact Zone $1=$ Tiesianwei, TSW; Impact Zone 2 = Shamaoushan, SM; Reference zone = Shertoushan, ST) in 2006-2007, at 2 depths (3 and 6 m)

\begin{tabular}{|c|c|c|c|c|c|c|}
\hline \multirow{2}{*}{$\begin{array}{l}\text { Environmental } \\
\text { parameter }\end{array}$} & \multicolumn{2}{|c|}{ - Impact Zone 1 (TSW)— } & \multicolumn{2}{|c|}{ — Impact Zone 2 (SM) } & \multicolumn{2}{|c|}{ — Reference zone (ST) } \\
\hline & $3 \mathrm{~m}$ & $6 \mathrm{~m}$ & $3 \mathrm{~m}$ & $6 \mathrm{~m}$ & $3 \mathrm{~m}$ & $6 \mathrm{~m}$ \\
\hline \multicolumn{7}{|l|}{$\mathrm{NH}_{4}-\mathrm{N}(\mu \mathrm{M})$} \\
\hline Range & $1.27-5.15$ & $0.48-5.63$ & $0.90-2.22$ & $0.33-2.52$ & $0.45-2.31$ & $0.42-2.59$ \\
\hline Mean \pm SE & $2.70 \pm 0.36$ & $2.66 \pm 0.49$ & $1.49 \pm 0.12$ & $1.32 \pm 0.18$ & $1.26 \pm 0.16$ & $1.10 \pm 0.19$ \\
\hline \multicolumn{7}{|l|}{$\mathrm{NO}_{3}-\mathrm{N}(\mu \mathrm{M})$} \\
\hline Range & $0.88-3.48$ & $1.10-3.63$ & $0.86-6.03$ & $0.70-3.69$ & $1.10-3.33$ & $0.92-4.32$ \\
\hline Mean $\pm \mathrm{SE}$ & $1.85 \pm 0.20$ & $1.86 \pm 0.24$ & $2.47 \pm 050$ & $2.02 \pm 0.28$ & $1.80 \pm 0.19$ & $1.99 \pm 0.31$ \\
\hline \multicolumn{7}{|l|}{$\mathrm{NO}_{2}-\mathrm{N}(\mu \mathrm{M})$} \\
\hline Range & $0.07-0.40$ & $0.10-0.39$ & $0.04-0.19$ & $0.05-0.29$ & $0.05-0.12$ & $0.03-0.12$ \\
\hline Mean $\pm \mathrm{SE}$ & $0.18 \pm 0.03$ & $0.20 \pm 0.02$ & $0.09 \pm 0.01$ & $0.09 \pm 0.02$ & $0.06 \pm 0.01$ & $0.07 \pm 0.01$ \\
\hline \multicolumn{7}{|l|}{$\mathrm{PO}_{4}-\mathrm{P}(\mu \mathrm{M})$} \\
\hline Range & $0.06-0.71$ & $0.07-0.60$ & $0.05-0.30$ & $0.05-0.32$ & $0.05-0.12$ & $0.05-0.18$ \\
\hline Mean $\pm \mathrm{SE}$ & $0.29 \pm 0.06$ & $0.32 \pm 0.06$ & $0.16 \pm 0.02$ & $0.16 \pm 0.02$ & $0.08 \pm 0.01$ & $0.10 \pm 0.01$ \\
\hline \multicolumn{7}{|c|}{ Suspended solids $\left(\mathrm{mg} \mathrm{l}^{-1}\right)$} \\
\hline Range & $10.55-30.45$ & $11.56-30.31$ & $9.19-27.64$ & $9.96-28.26$ & $9.79-27.11$ & $11.58-28.65$ \\
\hline Mean \pm SE & $21.94 \pm 1.67$ & $22.58 \pm 1.52$ & $18.48 \pm 1.89$ & $20.21 \pm 1.94$ & $19.04 \pm 1.63$ & $19.90 \pm 1.63$ \\
\hline \multicolumn{7}{|c|}{ Organic matter $\left(\mathrm{mg} \mathrm{l}^{-1}\right)$} \\
\hline Range & $2.85-9.47$ & $2.81-9.41$ & $2.24-9.10$ & $3.01-8.45$ & $2.33-8.54$ & $2.72-10.31$ \\
\hline Mean $\pm \mathrm{SE}$ & $6.38 \pm 0.56$ & $6.30 \pm 0.53$ & $5.05 \pm 0.58$ & $5.43 \pm 0.46$ & $5.23 \pm 0.51$ & $5.61 \pm 0.60$ \\
\hline \multicolumn{7}{|c|}{ Chlorophyll a $\left(\mu \mathrm{g}^{-1}\right)$} \\
\hline Range & $1.03-2.81$ & $0.94-2.37$ & $0.90-2.48$ & $0.90-2.49$ & $0.73-1.66$ & $0.87-1.92$ \\
\hline Mean \pm SE & $1.75 \pm 014$ & $1.74 \pm 0.11$ & $1.46 \pm 0.14$ & $1.60 \pm 0.15$ & $1.00 \pm 0.07$ & $1.37 \pm 0.09$ \\
\hline \multicolumn{7}{|c|}{ Dissolved oxygen $\left(\mathrm{mg} \mathrm{l}^{-1}\right)$} \\
\hline Range & $4.32-8.79$ & $4.15-8.92$ & $5.79-9.54$ & $5.71-9.43$ & $6.17-10.03$ & $6.01-9.66$ \\
\hline Mean \pm SE & $6.56 \pm 0.41$ & $6.45 \pm 0.43$ & $7.44 \pm 0.34$ & $7.34 \pm 0.35$ & $7.80 \pm 0.35$ & $7.87 \pm 0.34$ \\
\hline \multicolumn{7}{|c|}{ Sedimentation rate $\left(\mathrm{g} \mathrm{m}^{-2} \mathrm{~d}^{-1}\right)$} \\
\hline Range & $7.26-30.34$ & $13.88-60.79$ & $5.86-64.78$ & $6.37-62.52$ & $9.55-79.13$ & $15.02-84.12$ \\
\hline Mean \pm SE & $17.49 \pm 1.99$ & $39.62 \pm 3.71$ & $26.97 \pm 5.68$ & $35.03 \pm 6.14$ & $30.61 \pm 5.98$ & $48.16 \pm 6.42$ \\
\hline
\end{tabular}

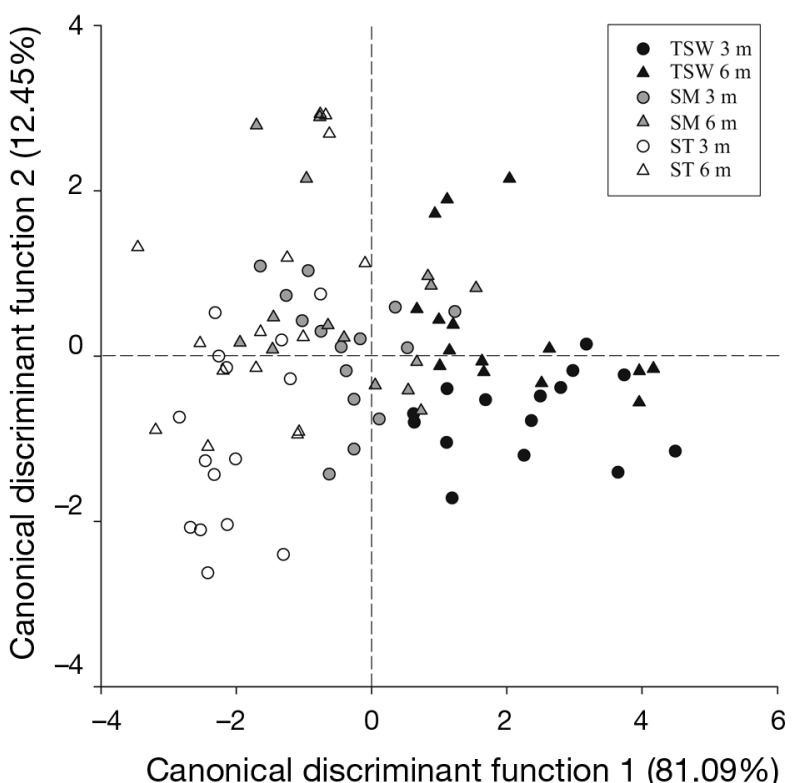

Fig. 2. Canonical discriminant analysis (CDA) of environmental parameters for the 3 sampled zones at Magongwan from August 2006 to December 2007. Impact Zone $1=$ Tiesianwei (TSW; black). Impact Zone 2 = Shamaoushan (SM; gray), Reference zone $=$ Shertoushan (ST; white). Transects at depths: $3 \mathrm{~m}$ (circles), $6 \mathrm{~m}$ (triangles). Data points: location + depth differences in coral coverage among the 3 zones $(F=$ 23.62, $\mathrm{p}<0.01)$ and 2 depths $(F=30.01, \mathrm{p}<0.01)$ (Table 3). The highest coral coverage extent at Magongwan was in Impact Zone 2 followed by Impact Zone 1, and was lowest in the reference zone, while the coverage extent at $3 \mathrm{~m}$ was higher than that at $6 \mathrm{~m}$. Mean values of macroalgal coverage in Impact Zone 1 were $59.4 \%(3 \mathrm{~m})$ and $61.1 \%(6 \mathrm{~m})$, and were significantly higher than those in the other zones $(F=98.21$, $\mathrm{p}<0.01,2$-way ANOVA) (Table 3). Moreover, macroalgal coverage significantly differed by depth $(F=$ 12.96, p < 0.01, 2-way ANOVA). The coverage extent of sponges/zoanthids in Impact Zone 1 (3.19 $\pm 0.99 \%$ at $3 \mathrm{~m}$ and $4.52 \pm 0.78 \%$ at $6 \mathrm{~m}$ ) was significantly higher than those in the other zones $(<1.00 \%)(F=29.16$, p < 0.01, 2-way ANOVA). No significant difference was detected in coverage extent between depths $(F=0.40$, $\mathrm{p}=0.53,2$-way ANOVA) (Table 3).

\section{Composition of coral communities and conservation values}

In total, 35 species in 24 genera from 13 families of reef coral species were identified at Magongwan in 
Table 2. Outcomes of total standardized canonical coefficients (TSCC) and total canonical structure coefficients (TCSC) between canonical discriminant functions (CDF1 and CDF2) and discriminant variables (environmental parameters) at Magongwan in 2006-2007. Relatively high absolute values are given in bold

\begin{tabular}{|c|c|c|c|c|}
\hline \multirow{2}{*}{$\begin{array}{l}\text { Discriminant } \\
\text { variable }\end{array}$} & \multicolumn{2}{|c|}{$-\mathrm{CDF} 1-$} & \multicolumn{2}{|c|}{$-\mathrm{CDF} 2$} \\
\hline & TSCC & TCSC & TSCC & TCSC \\
\hline $\mathrm{NH}_{4}-\mathrm{N}(\mu \mathrm{M})$ & 0.57 & 0.35 & -1.07 & -0.20 \\
\hline $\mathrm{NO}_{3}-\mathrm{N}(\mu \mathrm{M})$ & -0.02 & -0.02 & 0.15 & 0.10 \\
\hline $\mathrm{NO}_{2}-\mathrm{N}(\mu \mathrm{M})$ & 0.50 & 0.47 & -0.71 & -0.04 \\
\hline $\mathrm{PO}_{4}-\mathrm{P}(\mu \mathrm{M})$ & -0.03 & 0.40 & 1.62 & 0.03 \\
\hline Suspended solids $\left(\mathrm{mg} \mathrm{l}^{-1}\right)$ & -0.41 & 0.11 & -0.09 & 0.03 \\
\hline Organic matter $\left(\mathrm{mg} \mathrm{l}^{-1}\right)$ & 0.30 & 0.12 & -0.26 & -0.02 \\
\hline Chlorophyll a ( $\left.\mu \mathrm{g} \mathrm{l}^{-1}\right)$ & 1.08 & 0.30 & 0.70 & 0.34 \\
\hline Dissolved oxygen $\left(\mathrm{mg} \mathrm{l}^{-1}\right)$ & -0.93 & -0.23 & -0.07 & 0.02 \\
\hline Sedimentation rate $\left(\mathrm{g} \mathrm{m}^{-2} \mathrm{~d}^{-1}\right)$ & -0.37 & -0.12 & 0.88 & 0.52 \\
\hline Canonical correlation coefficient & 0.86 & & 0.56 & \\
\hline Eigenvalues & 2.86 & & 0.44 & \\
\hline Cumulative variance explained & 0.81 & & 0.94 & \\
\hline
\end{tabular}

coefficients of correlation between the original variable and the canonical variate are shown in Table 5 . The first canonical variate of the benthic organism communities mainly represented the macroalgae and sponges/zoanthids, and the canonical variate of environmental parameters mainly represented nutrients (nitrite, phosphate, and ammonium), chl $a$, and DO. These findings helped narrow the relationship between benthic organism communities and environmental parameters to a lower number of variables, and indicated the coverage of macroalgae and sponges/zoanthids was positively related to nutrients, chl $a$, and DO. this study. Coral coverage of the 5 top-ranked species in Impact Zone 2 accounted for $>59.5 \%$ of all live coral cover, and those in the other 2 zones accounted for $>81 \%$ of live coral cover (Table 4 ). Based on the morphological categories of the r-K-S ternary diagram, the 5 dominant coral species were Montipora cactus ( $\mathrm{K}_{\text {; }}$ K-strategist), Euphyllia paraancora (S; S-strategist), Goniopora columna (S), Lithophyllon undulatum (K), and Platygyra sinensis (S) in Impact Zone 1. Coral communities at both 3 and $6 \mathrm{~m}$ in Impact Zone 1 lacked branching Acropora corals ( $r_{i} r$-strategist) and were mostly composed of stress tolerators $(>60 \%$ of all coverage); hence, their positions on the r-K-S ternary diagram were assigned to CC1 (Fig. 4). Because of the variety of coral morphologies and functional groups, such as branching Acropora corals, the massive coral, G. columna (S), the encrusting coral, L. undulatum (K), and large monospecific stands of the foliose corals, Pavona decussata (K) and Turbinaria mesenterina (K), coral communities in Impact Zone 2 (3 and $6 \mathrm{~m}$ ) were assigned to $\mathrm{CC} 4$. Coral communities in the reference zone (3 and $6 \mathrm{~m}$ ) were assigned to CC3 due to a high coverage of branching Acropora corals (>56.1\% of all coverage), such as A. muricata, A. valida, and Pocillopora damicornis.

\section{Canonical correlations between the coverage of benthic organism communities and environmental parameters}

The CCA of benthic organism communities and environmental parameters revealed one significant set $(F=1.85, \mathrm{p}<0.05)$ of canonical variates, with a canonical correlation coefficient of 0.86 , which together explained $81.35 \%$ of the total variation of the data. The

\section{DISCUSSION}

\section{Nutrient enrichment of the water}

During the survey period, mean concentrations of nitrogenous nutrients in the impact zones were significantly higher, and their phosphate concentrations $(0.16-0.32 \mu \mathrm{m})$ were on average 2 - to 4 -fold higher than the average in the reference zone. Moreover, results of the CDA also showed that nutrients (ammonium, nitrite, and phosphate) were the main parameters significantly distinguishing Impact Zone 1 from the other zones. This finding is similar to those from previous studies. Villanueva et al. (2005) showed higher levels of ammonium (almost $7.00 \mu \mathrm{M}$ ) and phosphate (almost $0.85 \mu \mathrm{M}$ ) in coral-reef waters around a fish farm in the Philippines, and La Rosa et al. (2002) also found that concentrations of phosphate at a fish farm site in the Tyrrhenian Sea (in the western Mediterranean) were up to 6-fold higher than that of the control.

Theoretically, the environmental impacts of marine cage culture depend on the feed types and hydrography of the site ( $\mathrm{Wu}$ 1995). High levels of ammonia in the water are detrimental to marine organisms and can be derived from the decomposition of nitrogenous compounds, such as aquafeed (Wu et al. 1994). In the Asian-Pacific region, low-priced trash fish with high nitrogenous contents are commonly used as feed in fish farming. Trash fish used as aquafeed sometimes induce environmental risks due to high decomposition rates that contribute to an overload of organic matter (Chen \& Hsu 2006, Xu et al. 2007). Nevertheless, water quality in semi-closed embayments is mainly influenced by local hydrologic conditions, including tidal flushing, water residence times, and tidal-driven water 

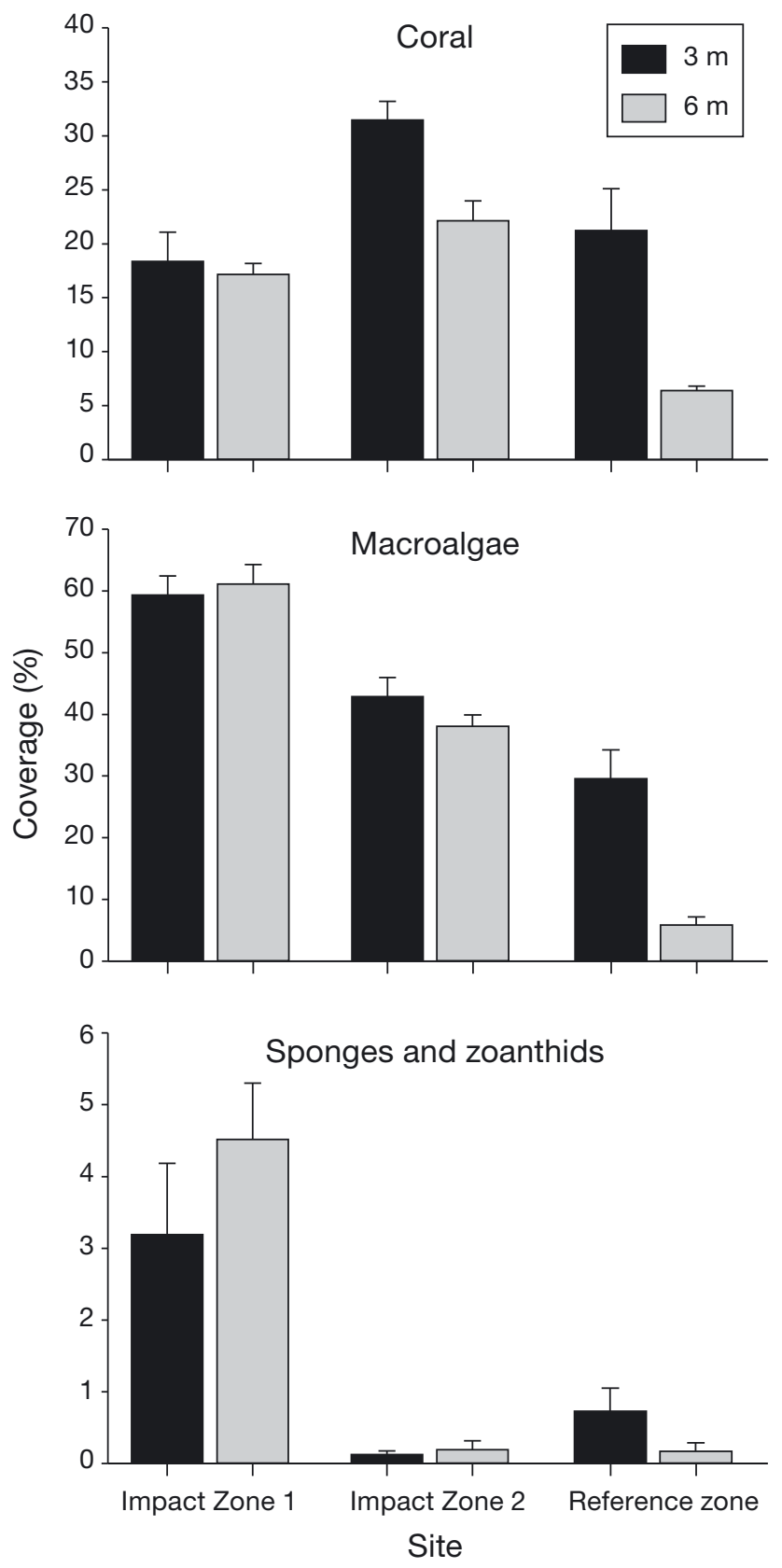

Fig. 3. Coverage $+\mathrm{SE}(n=6)$ of coral, macroalgae (including turf algae on dead corals), and sponges/zoanthids along 6 random photographic transects at 2 depths ( 3 and $6 \mathrm{~m}$ ) in Magongwan in August 2006 currents (Grall \& Chauvaud 2002, Mayor et al. 2010). Piriou \& Menesguen (1992) revealed that strong currents usually prevent eutrophication by flushing nutrients out of an ecosystem. Wu et al. (1994) observed a decrease in the DO and an increase in nutrient concentrations at a fish farm in Hong Kong with poor tidal flushing, a low current velocity $\left(<2 \mathrm{~cm} \mathrm{~s}^{-1}\right)$, and a high stocking density. At Magongwan, elevated levels of nutrients, TSS, and organic matter were also detected in the impact zones (1 and 2) where the current velocity was $<10 \mathrm{~cm} \mathrm{~s}^{-1}$, suggesting that trash fish used as aquafeed could affect the water quality, and hydrologic conditions might not easily flush excessive nutrients out of Magongwan.

\section{Overgrowth of macroalgae and benthic filter feeders}

Results of this study showed that nutrient enrichment at Magongwan stimulated macroalgal overgrowth and increased primary production in the water. Concentrations of dissolved inorganic nitrogen (DIN; $4.73 \mu \mathrm{m}$; including ammonium, nitrite, and nitrate) and phosphate in the impact zones were all above nutrient thresholds noted for macroalgal overgrowth $(1.0 \mu \mathrm{m}$ DIN and $<0.1 \mu \mathrm{m}$ soluble reactive phosphorus) as demonstrated by Lapointe (1997). Macroalgae and phytoplankton can rapidly assimilate the higher amounts of available nutrients and are adapted to high-nutrient, eutrophic waters, and macroalgal cover was shown to decrease after sewage dilution (Done 1992; referred to in Fabricius 2005). Moreover, McCook (1999) expressed the concern that degradation of inshore coral reefs of the Great Barrier Reef (GBR), caused by terrestrial input of sediment and nutrients, was always accompanied by abundant macroalgae. Therefore, it is evident that macroalgal abundance increased with extra nutrient supplies in the culture zone, and thus that the nutrient enrichment and macroalgal overgrowth at Magongwan represent warning signs that the environment is undergoing degradation. Fabricius (2005) stated that the consequences of nutrient enrichment of coral reefs not only cause macroalgal overgrowth, but also increase densities of benthic

Table 3. Results of 2-way ANOVA of the coverage of coral, macroalgae, and sponges/zoanthids at Magongwan. ${ }^{*} \mathrm{p}<0.05,{ }^{* *} \mathrm{p}<$ 0.01, ns: non-significant

\begin{tabular}{|c|c|c|c|c|c|c|c|c|c|c|c|c|}
\hline \multirow[t]{2}{*}{ Source of variation } & \multicolumn{4}{|c|}{ Coral } & \multicolumn{4}{|c|}{ Macroalgae } & \multicolumn{4}{|c|}{ Sponges and zoanthids } \\
\hline & $\mathrm{df}$ & MS & $F$ & $\mathrm{p}$ & $\mathrm{df}$ & MS & $F$ & $\mathrm{p}$ & $\mathrm{df}$ & MS & $F$ & $\mathrm{p}$ \\
\hline Zone & 1 & 711.246 & 23.623 & $* *$ & 1 & 5435.323 & 98.204 & ** & 1 & 50.624 & 29.159 & ** \\
\hline Depth & 2 & 903.644 & 30.013 & ** & 2 & 717.097 & 12.956 & ** & 2 & 0.695 & 0.400 & ns \\
\hline Zone $\times$ Depth & 2 & 253.516 & 8.420 & $* *$ & 2 & 523.646 & 9.461 & $* *$ & 2 & 2.767 & 1.594 & ns \\
\hline
\end{tabular}


Table 4. Coverage (\%) and morphological categories of the 5 top-ranked coral species at Impact Zones 1 (Tiesianwei, TSW) and 2 (Shamaoushan, SM), and the reference zone (Shertoushan, ST) in Magongwan, at 2 depths (3 and 6 m). Coral morphological categories are identified as r-K-S coral groups (r: ruderals; K: competitors; S: stress-tolerators)

\begin{tabular}{|c|c|c|c|c|c|}
\hline \multicolumn{2}{|c|}{ Impact Zone 1 (TSW) } & \multicolumn{2}{|c|}{ - Impact Zone 2 (SM) -} & $\begin{array}{l}\text { Reference zone } \\
\text { Species (r-K-S group) }\end{array}$ & $\begin{array}{l}\text { e }(\mathrm{ST})-\overline{\text { Coral cover }(\%)} \\
\text { Coral }\end{array}$ \\
\hline \multicolumn{6}{|l|}{$3 \mathbf{m}$} \\
\hline Montipora cactus (K) & $5.89 \pm 1.12$ & Acropora muricata (r) & $6.85 \pm 3.07$ & Montipora cactus (K) & $5.27 \pm 1.16$ \\
\hline Goniopora columna (S) & $4.63 \pm 1.11$ & Pavona decussata (K) & $4.76 \pm 1.82$ & Acropora muricata (r) & $5.24 \pm 1.26$ \\
\hline Platygyra sinensis $(\mathrm{S})$ & $2.43 \pm 0.87$ & Acropora humilis (r) & $4.00 \pm 1.40$ & Porites lutea (S) & $3.00 \pm 0.98$ \\
\hline Galaxea fascicularis (S) & $1.33 \pm 0.61$ & Goniopora columna (S) & $3.67 \pm 1.02$ & Acropora valida (r) & $2.09 \pm 0.95$ \\
\hline Pavona decussata (K) & $0.96 \pm 0.41$ & Montipora cactus (K) & $1.80 \pm 0.74$ & Pavona decussata (K) & $1.69 \pm 0.61$ \\
\hline$\%$ of total coral species & 83.06 & $\%$ of total coral species & 67.00 & $\%$ of total coral species & 81.46 \\
\hline \multicolumn{6}{|l|}{$6 \mathrm{~m}$} \\
\hline Euphyllia paraancora (S) & $5.13 \pm 1.65$ & Acropora muricata (r) & $3.68 \pm 1.19$ & Porites lutea (S) & $1.83 \pm 0.45$ \\
\hline Lithophyllon undulatum (K) & $3.03 \pm 1.03$ & Pavona decussata (K) & $3.14 \pm 0.62$ & Acropora valida (r) & $2.74 \pm 0.30$ \\
\hline Goniopora columna (S) & $2.57 \pm 0.57$ & Lithophyllon undulatum (K) & $2.88 \pm 0.56$ & Montipora cactus K) & $1.06 \pm 0.03$ \\
\hline Turbinaria mesenterina (K) & $1.60 \pm 0.34$ & Acropora humilis (r) & $1.79 \pm 0.59 \quad I$ & Pocillopora damicornis (r) & $1.04 \pm 0.02$ \\
\hline Echinophyllia aspera (K) & $1.58 \pm 0.64$ & Turbinaria mesenterina (K) & $1.66 \pm 0.66$ & Acropora muricata (r) & $1.03 \pm 0.01$ \\
\hline$\%$ of total coral species & 80.98 & $\%$ of total coral species & 59.45 & $\%$ of total coral species & 100.00 \\
\hline
\end{tabular}

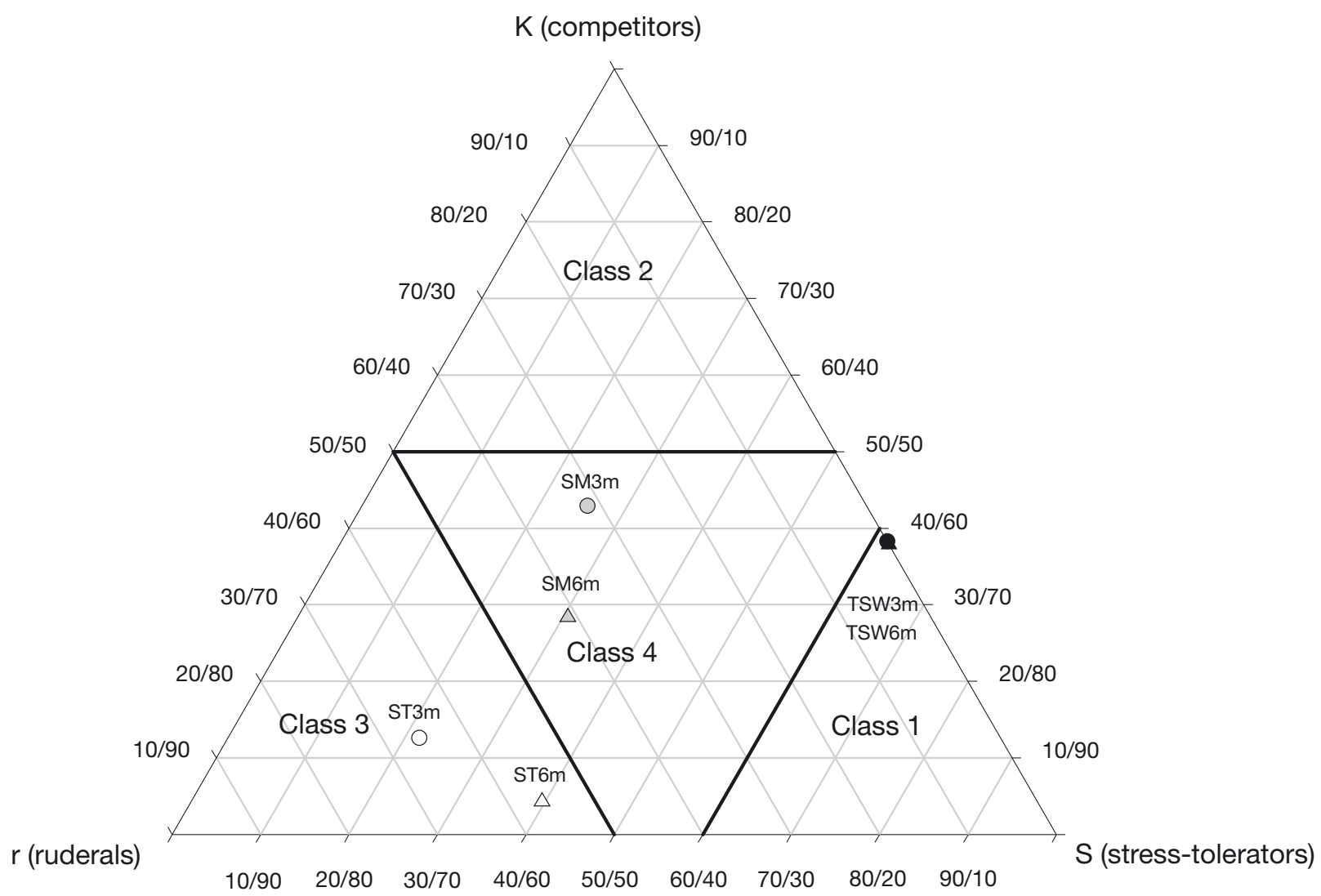

Fig. 4. All study sites plotted on an r-K-S ternary diagram $(n=6)$, and the conservation classes in the Penghu Islands. Impact Zones 1 and 2: TSW (black) and SM (gray), respectively; Reference zone: ST (white). Depths: $3 \mathrm{~m}$ (triangles), $6 \mathrm{~m}$ (circles). See Fig. 2 for definitions

filter feeders, such as sponges, bivalves, ascidians, bryozoans, and barnacles. Because excessive nutrients enhance the phytoplankton biomass, primary productivity, and turbidity in the water, these benthic filter feeders quickly grow and pullulate by taking up surplus organic matter and particles from turbid waters (Pastorok \& Bilyard 1985). In this study, sponges and zoanthids were flourishing in Impact Zone 1 (with 
Table 5. Canonical structures of the first set of original variables ( 3 benthic organism communities and 9 environmental parameters) and their canonical variates. Relatively high values are given in bold

\begin{tabular}{|c|c|}
\hline Original variable & Canonical variate \\
\hline \multicolumn{2}{|l|}{ Benthic organism communities } \\
\hline Coral (\%) & 0.13 \\
\hline Macroalgae (\%) & 0.80 \\
\hline Sponges and zoanthids (\%) & 0.87 \\
\hline \multicolumn{2}{|l|}{ Environmental parameters } \\
\hline $\mathrm{NH}_{4}-\mathrm{N}(\mu \mathrm{M})$ & 0.58 \\
\hline $\mathrm{NO}_{3}-\mathrm{N}(\mu \mathrm{M})$ & -0.05 \\
\hline $\mathrm{NO}_{2}-\mathrm{N}(\mu \mathrm{M})$ & 0.76 \\
\hline $\mathrm{PO}_{4}-\mathrm{P}(\mu \mathrm{M})$ & 0.61 \\
\hline Suspended solids $\left(\mathrm{mg} \mathrm{l}^{-1}\right)$ & 0.23 \\
\hline Organic matter $\left(\mathrm{mg} \mathrm{l}^{-1}\right)$ & 0.25 \\
\hline Chlorophyll a $\left(\mu \mathrm{g} \mathrm{l}^{-1}\right)$ & 0.44 \\
\hline Dissolved oxygen $\left(\mathrm{mg} \mathrm{l}^{-1}\right)$ & 0.50 \\
\hline Sedimentation rate $\left(\mathrm{g} \mathrm{m}^{-2} \mathrm{~d}^{-1}\right)$ & -0.14 \\
\hline
\end{tabular}

$>3.19 \%$ coverage) that possessed high levels of nutrients, chl $a$, TSS, and organic matter. These consequences of effluents released from the cages may support the overgrowth of benthic filter feeders at Magongwan.

\section{Composition of coral communities at Magongwan}

Well-developed coral communities are characterized by both high coral coverage and biodiversity (Hsieh et al. 2001, 2007, Cooper et al. 2009), but coral coverage alone is not sufficient. Recently, ternary diagrams of the conservation class (CC) to classify coral morphology categories (r-K-S) were recognized as a more-reliable predictor of reef conditions, habitat complexity, and species richness than was live coral coverage (Edinger \& Risk 2000, Hsieh et al. 2007). In this study, coral coverage in Impact Zone 1 (18.36\% at $3 \mathrm{~m}$ and $17.17 \%$ at $6 \mathrm{~m}$ ) did not statistically differ from those of Impact Zone $2(22.11 \%$ at $6 \mathrm{~m})$ or the reference site $(21.23 \%$ at $3 \mathrm{~m})$, but results of the 5 topranked coral species ( $>59 \%$ of all) at Magongwan showed that the composition of coral communities in Impact Zone 1 completely differed from the other zones. Because marine cage culture and other related activities are the main pollution source at Magongwan, and Rogers (1990) and Stafford-Smith \& Ormond (1992) revealed that coral community compositions might have been affected by nutrient enrichment, sedimentation, and turbidity, the 6 surveyed sites were generally classified into 2 main community types by the dominant coral morphology categories: (1) Impact Zone 1, mainly composed of Euphyllia spp.,
Platygyra spp., Goniopora spp., and Lithophyllon spp. and (2) the other zones, mainly composed of diverse coral species and dominant branching Acropora corals, such as A. muricata, A. humilis, and A. valida and the foliose coral, Pavona sp. The r-K-S ternary diagrams also classified Impact Zone 1 in the low level (CC1) due to a lack of live branching Acropora corals and domination by S-strategist corals, such as massive and submassive corals. Hence, the results of the r-K-S ternary diagrams imply that coral communities in Impact Zone 1 are under threat of marine eutrophication. Those in Impact Zone 2 (3 and $6 \mathrm{~m}$ ), which is $800 \mathrm{~m}$ from the cages, were estimated to have a high conservation value (CC4) due to the dominance of branching Acropora and other tabular coral communities, and diverse morphologies of coral species. Particularly, Impact Zone 2 at $3 \mathrm{~m}$ had the highest coverage $(31.45 \pm 1.75 \%)$ and species number (26 species), and concentrations of nutrients, POM, and chl a ranged between those of Impact Zone 1 and the reference zone. Although nutrient enrichment may stress nearby coral reefs, the outcome of nutrient enrichment actually depends on the chemical forms and concentrations of the nutrients (Ferrier-Pagès et al. 2000). Moreover, corals not only can and do flourish in relatively high-nutrient waters (Atkinson et al. 1995), but they may also grow and reproduce faster and have even exhibited high survivorship under the influence of fish farm effluents (Bongiorni et al. 2003a,b, Shahir et al. 2006, Amar \& Rinkevich 2007, Shaish et al. 2008). In turbid and low-light waters, corals demonstrate the capacity to exploit nutrient sources by shifting from autotrophy to heterotrophy (Anthony 1999a,b, 2000, Anthony \& Fabricius 2000) and use the extra POM and sediments as additional food sources (Rosenfeld et al. 1999, Anthony \& Fabricius 2000, Bongiorni et al. 2003a). Those reports support coral communities in Impact Zone 2 flourishing in the turbid water at Magongwan. Elevated levels of nutrients in reefs are always accompanied by an increase in benthic filter feeder and macroalgae abundance, and the competition among corals, macroalgae, and benthic filter feeders may lead to a dominance shift in communities (Costa et al. 2008). During the survey period, abundant large-scale broken fragments of dead branching Acropora corals covered by turf algae were observed in Impact Zone 1 (authors' pers. obs.). Furthermore, the Penghu Islands are under the threat of overfishing and reduction in grazing pressure by herbivorous organisms (Dai et al. 2002). It is possible that chronic nutrient enrichment caused by cage culture at Magongwan has influenced the overgrowth of macroalgal and benthic filter feeder communities, which might have affected some branching Acropora corals. 


\section{Overall impacts of marine cage culture on coral communities of the Penghu Islands}

Our study provides preliminary results suggesting that nutrient enrichment was likely caused by cage culture during the survey period (2006 to 2007), although this result could alternatively have been influenced by the environmental conditions of past years, for which we lack data. We investigated the idea that eutrophication by cage culture effluents may have altered suitable habitats for coral reef organisms of this region, and local hydrology and feed type could also have influenced our findings. Subtropical coral communities in the Penghu Islands may be more influenced by nutrient enrichment than turbidity and sedimentation. Consequently, this study suggests that chronic nutrient enrichment caused by marine cage culture might have negative implications for the surrounding waters, influencing interactions between macroalgae and corals. The most effective ways to minimize the risk of environmental degradation are to restrict the expansion of culture sites, remove cage culture, or allow areas to remain fallow (Loya 2007). It is hoped that these suggestions will provide insights for local governments to develop appropriate conservation management strategies, and for fishery authorities and aquaculture planning agencies to maintain a functional marine environment.

Acknowledgements. We thank the Penghu County Marine Life Proliferation Center and Penghu Marine Biological Research Center, a facility of the Taiwan Fishery Research Institute, for logistical support throughout the field studies in Penghu, and members of the Coral Reef Evolutionary Ecology and Genetics (CREEG) laboratory, Biodiversity Research Center, Academia Sinica (BRCAS), 4 anonymous referees, and Dr. P. Edmunds for constructive comments. C.A.C. is the recipient of the Australian Endeavour Award and National Science Council (NSC)-Australian Academy of Science Fellowship. Y.A.H. is the recipient of a NSC PhD fellowship (2006-2008), and K.S. is the recipient of a post-doctoral fellowship (2008-2010) NSC, Taiwan. This study was made possible by grants from Academia Sinica and the NSC (NSC 952313-B-001-022-MY3), Taiwan to C.A.C. This is the CREEGBRCAS contribution no. 62 .

\section{LITERATURE CITED}

Abelson A, Olinky R, Gaines S (2005) Coral recruitment to the reefs of Eliat, Red Sea: temporal and spatial, and possible effects of anthropogenic disturbances. Mar Pollut Bull 50: $576-582$

Amar KO, Rinkevich B (2007) A floating mid-water coral nursery as larval dispersion hub: testing an idea. Mar Biol 151:713-718

Anthony KRN (1999a) Coral suspension feeding on fine particulate matter. J Exp Mar Biol Ecol 232:85-106

> Anthony KRN (1999b) A tank system for studying benthic aquatic organisms at predictable levels of turbidity and sedimentation: case study examining coral growth. Limnol Oceanogr 44:1415-1422

Anthony KRN (2000) Enhanced particle-feeding capacity of corals on turbid reefs (Great Barrier Reef, Australia). Coral Reefs 19:59-67

Anthony KRN, Fabricius KE (2000) Shifting roles of heterotrophy and autotrophy in coral energetics under varying turbidity. J Exp Mar Biol Ecol 252:221-253

Atkinson MJ, Carlson B, Crow GL (1995) Coral growth in high-nutrient, low pH seawater: a case study of corals cultured at the Waikiki Aquarium, Honolulu, Hawaii. Coral Reefs 14:215-223

Bongiorni L, Shafir S, Angel D, Rinkevich B (2003a) Survival, growth and gonad development of two hermatypic corals subjected to in situ fish-farm nutrient enrichment. Mar Ecol Prog Ser 253:137-144

Bongiorni L, Shafir S, Rinkevich B (2003b) Effects of particulate matter released by a fish farm (Eilat, Red Sea) on survival and growth of Stylophora pistillata coral nubbins. Mar Pollut Bull 46:1120-1124

Brown JR, Gowen RJ, McLusky DS (1987) The effect of salmon farming on the benthos of a Scottish sea loch. J Exp Mar Biol Ecol 109:39-51

Bruno JF, Petes LE, Harvell CD, Hettinger A (2003) Nutrient enrichment can increase the severity of coral diseases. Ecol Lett 6:1056-1061

Chen CA (1999) Analysis of scleractinian distribution in Taiwan indicating a pattern congruent with sea surface temperatures and current: examples from Acropora and Faviidae corals. Zool Stud 38:119-129

Chen YS, Hsu CY (2006) Ecological considerations of cage aquaculture in Taiwan. J Fish Soc Taiwan 33:139-146

Cooper TF, Gilmour JP, Fabricius KE (2009) Bioindicators of changes in water quality on coral reefs: review and recommendations for monitoring programmes. Coral Reefs 28: 589-606

Costa OS Jr, Nimmo M, Attrill MJ (2008) Coastal nutrification in Brazil: a review of the role of nutrient excess on coral reef demise. J S Am Earth Sci 25:257-270

Dai CF, Soong KY, Chen CA, Huang JS, Fan TY, Hsieh HY, Chang JS (2002) The status of coral reefs in Taiwan and the conservation problems. Proc IUCN/WCPA-EA-4 Taipei Conf, March 18-23, Taipei, p 266-276

Done TJ (1992) Phase shifts in coral reef communities and their ecological significance. Hydrobiologia 247:121-132

- Edinger EN, Risk MJ (2000) Reef classification by coral morphology predicts coral reef conservation value. Biol Conserv 92:1-13

Fabricius KE (2005) Effects of terrestrial runoff on the ecology of corals and coral reefs: review and synthesis. Mar Pollut Bull 50:125-146

> Ferrier-Pagès C, Guttuso JP, Dallot S, Jaubert J (2000) Effect of nutrient enrichment on growth and photosynthesis of the zooxanthellate coral Stylophora pistillata. Coral Reefs 19:103-113

> Gao QF, Cheung KL, Cheung SG, Shin PKS (2005) Effects of nutrient enrichment derived from fish farming activities on macroinvertebrate assemblages in a subtropical region of Hong Kong. Mar Pollut Bull 51:994-1002

Garren M, Smriga S, Azam F (2008) Gradients of coastal fish farm effluents and their effect on coral reef microbes. Environ Microbiol 10:2299-2312

> Grall J, Chauvaud L (2002) Marine eutrophication and benthos: the need for new approaches and concepts. Glob Change Biol 8:813-830

> Holmer M, Argyrou M, Dalsgaard T, Danovaro R and others (2008) Effects of fish farm waste on Posidonia oceanica 
meadows: synthesis and provision of monitoring and management tools. Mar Pollut Bull 56:1618-1629

Hsieh HJ, Lu YI, Tsai WS, Wei NV, Jeng MS, Chen CA (2001) Unexpectedly high coral coverage in Chinwan Inner Bay, Pescadores: a proposed site for a marine protection area. Coral Reefs 20:316-317

> Hsieh HJ, Chen CA, Dai CF, Ou WS, Tsai WS, Su WC (2007) From the drawing board to the field: an example for establishing an MPA in Penghu, Taiwan. Aquat Conserv: Mar Freshw Ecosyst 17:619-635

$\mathrm{Hu} \mathrm{HH}$, Liu CY, Tsai WS (1986) Report of marine culture in Penghu, Taiwan. Fishery Research Institute, Makong

Jackson JBC, Kirby MX, Wolfgang HB, Bjorndal KA and others (2001) Historical overfishing and the recent collapse of coastal ecosystems. Science 293:629-637

Karakassis I, Tsapakis M, Smith CJ, Rumohr H (2002) Fish farming impacts in the Mediterranean studied through sediment profile imagery. Mar Ecol Prog Ser 227:125-133

Kohler KE, Gill SM (2006) Point Count with Excel extensions (CPCe): a Visual Basic program for the determination of coral and substrate coverage using random point count methodology. Comput Geosci 32:1259-1269

Koop K, Booth D, Broadbent A, Brodie J, and others (2001) ENCORE: the effect of nutrient enrichment on coral reefs: synthesis of results and conclusions. Mar Pollut Bull 42: 91-120

La Rosa T, Mirto S, Favaloro E, Savona B, Sarà G, Danovaro R, Mazzola A (2002) Impact on the water column biogeochemistry of a Mediterranean mussel and fish farm. Water Res 36:713-721

Lapointe BE (1997) Nutrient thresholds for eutrophication and macroalgal overgrowth of coral reefs in Jamaica and southeast Florida. Limnol Oceanogr 42:1119-1131

Loya Y (2007) How to influence environmental decision makers? The case of Eilat (Red Sea) coral reefs. J Exp Mar Biol Ecol 344:35-53

Loya Y, Kramarsky-Winter E (2003) In situ eutrophication caused by fish farms in the northern Gulf of Eilat (Aqaba) is beneficial for its coral reefs: a critique. Mar Ecol Prog Ser 261:299-303

Loya Y, Lubinevsky H, Rosenfeld M, Kramarsky-Winter E (2004) Nutrient enrichment caused by in situ fish farms at Eilat, Red Sea is detrimental to coral reproduction. Mar Pollut Bull 49:344-353

Mayor DJ, Zuur AF, Solan M, Paton GI, Killham K (2010) Factors affecting benthic impacts at Scottish fish farms. Environ Sci Technol 44:2079-2084

> McCook LK (1999) Macroalgae, nutrients and phase shift on coral reefs: scientific issues and management consequences for the Great Barrier Reef. Coral Reefs 18: 357-367

Meng PJ, Lee HJ, Wang JT, Chen CC, Lin HJ, Tew KS, Hsieh WJ (2008) A long-term survey on anthropogenic impacts to the water quality of coral reefs, southern Taiwan. Environ Pollut 156:67-75

Paerl HW, Dyble J, Moisander PH, Noble RT and others (2003) Microbial indicators of aquatic ecosystem change: current applications to eutrophication studies. FEMS Microbiol Ecol 46:233-246

Pastorok RA, Bilyard GR (1985) Effects of sewage pollution on coral-reef communities. Mar Ecol Prog Ser 21:175-189

Editorial responsibility: Peter Edmunds,

Northridge, California, USA
Piriou JY, Menesguen A (1992) Environmental factors controlling the Ulva sp. blooms in Brittany (France). In: Colombo G, Ferrari I, Ceccherelli VU, Rossi R (eds) Marine eutrophication and population dynamics. Proc 25th Eur Mar Bio Symp. Olsen \& Olsen, Fredensburg, p 111-116

Rinkevich B (2005a) Nutrient enrichment and coral reproduction: between truth and repose (a critique of Loya et al.). Mar Pollut Bull 50:111-113

Rinkevich B (2005b) What do we know about Eilat (Red Sea) reef degradation? A critical examination of the published literature. J Exp Mar Biol Ecol 327:183-200

Rinkevich B, Angel D, Shafir S, Bongiorni L (2003) Fair is foul and foul is fair: response to a critique. Mar Ecol Prog Ser 261:305-309

- Rogers CS (1990) Responses of coral reefs and organisms to sedimentation. Mar Ecol Prog Ser 62:185-202

> Rosenfeld M, Bresler V, Abelson A (1999) Sediment as a possible source of food for corals. Ecol Lett 2:345-348

> Shafir S, Rijn VJ, Rinkevich B (2006) Steps in the construction of underwater coral nursery, an essential component in reef restoration acts. Mar Biol 149:679-687

Shaish L, Levy G, Gomez E, Rinkevich B (2008) Fixed and suspended coral nurseries in the Philippines: establishing the first step in the 'gardening concept' of reef restoration. J Exp Mar Biol Ecol 358:86-97

Shrestha S, Kazama F (2007) Assessment of surface water quality using multivariate statistical techniques: a case study of the Fuji River basin, Japan. Environ Model Softw 22:464-475

Stafford-Smith MG, Ormond RFG (1992) Sediment-rejection mechanisms of 42 species of Australian scleractinian corals. Aust J Mar Freshw Res 43:683-705

Szmant AM (2002) Nutrient enrichment on coral reefs: Is it a major cause of coral reef decline? Estuaries 25:743-766

> Villanueva RD, Yap HT, Montano MNE (2005) Survivorship of coral juveniles in a fish farm environment. Mar Pollut Bull 51:580-589

- Villanueva RD, Yap HT, Montano MNE (2006) Intensive fish farming in the Philippines is detrimental to the reefbuilding coral Pocillopora damicornis. Mar Ecol Prog Ser 316:165-174

> Weston DP (1990) Quantitative examination of macrobenthic community changes along an organic enrichment gradient. Mar Ecol Prog Ser 61:233-244

Wielgus J (2003) The coral reef of Eilat (northern Red Sea) requires immediate protection. Mar Ecol Prog Ser 263:307

Wu RSS (1995) The environmental impact of marine fish culture: towards a sustainable future. Mar Pollut Bull 31: 159-166

Wu RSS, Lam KS, MacKay DW, Lau TC, Yam V (1994) Impact of marine fish farming on water quality and bottom sediment: a case study in the sub-tropical environment. Mar Environ Res 38:115-145

> Xu Z, Lin X, Lin Q, Yang Y, Wang Y (2007) Nitrogen, phosphorus, and energy waste outputs of four marine cage-cultured fish fed with trash fish. Aquaculture 263: 130-141

> Yucel-Gier G, Kucuksezgin F, Kocak F (2007) Effects of fish farming on nutrients and benthic community structure in the eastern Aegean (Turkey). Aquacult Res 38:256-267

Submitted: March 15, 2010; Accepted: November 17, 2010 Proofs received from author(s): January 31, 2011 